\title{
Braking Dopamine Systems: A New GABA Master Structure for Mesolimbic and Nigrostriatal Functions
}

\author{
Michel Barrot, ${ }^{1}$ Susan R. Sesack, ${ }^{2}$ François Georges, ${ }^{3,4}$ Marco Pistis, ${ }^{5}$ Simon Hong, ${ }^{6}$ and Thomas C. Jhou ${ }^{7}$ \\ ${ }^{1}$ Institut des Neurosciences Cellulaires et Intégratives, Centre National de la Recherche Scientifique, Université de Strasbourg, 67084 Strasbourg, France, \\ 2Department of Neuroscience and Department of Psychiatry, University of Pittsburgh, Pittsburgh, Pennsylvania 15260, ${ }^{3}$ Université de Bordeaux, \\ Interdisciplinary Institute for Neuroscience, UMR 5297, F-33000 Bordeaux, France, ${ }^{4}$ Centre National de la Recherche Scientifique, Interdisciplinary \\ Institute for Neuroscience, UMR 5297, F-33000 Bordeaux, France, ${ }^{5}$ Department of Biomedical Sciences, University of Cagliari, 09042 Monserrato, Italy, \\ ${ }^{6}$ Laboratory of Sensorimotor Research, National Eye Institute/National Institutes of Health, Bethesda, Maryland 20892, and ${ }^{7}$ Medical University of South \\ Carolina, Department of Neurosciences, Charleston, South Carolina 29425
}

A new mesopontine structure exerting a strong influence on dopamine systems has recently been defined: the tail of the ventral tegmental area/rostromedial tegmental nucleus (tVTA/RMTg). This review presents a neuroanatomical, physiological, and behavioral overview of some of the recent and ongoing research on this brain region and its relationship with dopamine systems. The tVTA/RMTg sends dense GABA projections to VTA and substantia nigra neurons. The inhibitory influence of tVTA/RMTg on dopamine neurons is supported by both neuroanatomical and electrophysiology data. The latter studies also reveal the tVTA/RMTg as a substrate for morphine and cannabinoid action on dopamine cells. In primates, the tVTA/RMTg has been implicated in reward prediction error signals, through a basal ganglia-lateral habenula-tVTA/RMTg-dopamine- basal ganglia circuit. In rodents, the tVTA/RMTg has been shown to play a critical role in aversive behaviors, particularly those involving behavioral inhibition, such as freezing and avoidance. These findings highlight the functional importance of the tVTA/RMTg as a major GABA brake for dopamine systems.

\section{Introduction}

In the past, sporadic studies have noted distinctive characteristics of a brain region (Herkenham and Nauta, 1979; Scammell et al., 2000; Jhou, 2005; Perrotti et al., 2005; Ikemoto, 2007; Olson and Nestler, 2007; Ferreira et al., 2008; Geisler et al., 2008; Rotllant et al., 2010) that is now recognized as the "tail of the ventral tegmental area" (Perrotti et al., 2005) or "rostromedial tegmental nucleus" (Jhou et al., 2009a) (tVTA/ RMTg). However, systematic study of this region was hampered by the lack of a coherent understanding of its anatomical and functional properties. This situation has now begun to change (Barrot and Thome, 2011; Lavezzi and Zahm, 2011; Bourdy and Barrot, 2012).

Anatomically, the tVTA/RMTg region (Fig. 1) has been shown to express a distinct pattern of afferents and efferents, including

Received July 16, 2012; revised Aug. 13, 2012; accepted Aug. 16, 2012.

This work was supported by the Centre National de la Recherche Scientifique (M.B., F.G.), the Université de Strasbourg (M.B.), the Université Bordeaux Segalen (F.G.), Agence Nationale de la Recherche Grant ANT-11-bsv4002 (M.B., F.G.), U.S. Public Health Service Grant MH067937 (S.R.S.), Italian Ministry of University Grant PRIN $200928 \mathrm{EEX}$ (M.P.), the intramural research program of the National Eye Institute (S.H.), National Institutes of Health Grants MH094489 and DA034431 (T.J.), the State of California Research Program for Alcoholism and Addiction (T.J.), the Intramural Research Program of NIH-NIDA (T.J.), and the Medical University of South Carolina (T.J.).

M.B. has received lecture fees from Adir (Servier) and from Lilly France, a research contractor funding from Missions-Cadres, and reports a CNRS-filed patent for new pain treatments. Those were unrelated to the topic of this Mini-Symposium. The other authors declare no competing financial interests.

Correspondence should be addressed to Michel Barrot at the above address. E-mail: mbarrot@inci-cnrs.unistra.fr.

S. Hong's present address: Massachusetts Institute of Technology, McGovern Institute of Brain Research, 43 Vassar Street, Cambridge, MA 02139.

DOI:10.1523/JNEUROSCI.3370-12.2012

Copyright $\odot 2012$ the authors $\quad 0270-6474 / 12 / 3214094-08 \$ 15.00 / 0$ strikingly focused afferents from the lateral habenula and strong projections to midbrain dopamine neurons, the dorsal raphe, and pedunculopontine nucleus (Jhou et al., 2009a,b; Kaufling et al., 2009, 2010a; Gonçalves et al., 2012), all regions that are implicated in motivated behavior. Rostrally, the tVTA/RMTg is bilaterally inserted deep into the posterior VTA, in a subregion of the paranigral nucleus and dorsolateral to the interpeduncular nucleus. In brain atlases, this part of the tVTA/RMTg is not yet differentiated from the VTA itself, and the tVTA/RMTg has strong neuroanatomical and functional links with dopamine systems, hence the designation as "tVTA." More caudally, the tVTA/ RMTg resides lateral to the median raphe, and partially embedded within the decussation of the superior cerebellar peduncle, at least in rats. This caudal half of the structure extends to the rostral edge of the pedunculopontine nuclei and shares homology with tegmental structures. Consistent with the nomenclature of other mesopontine structures and tegmental nuclei, it is thus designated as "RMTg." However, both names refer to the same tVTA/RMTg continuum, which is proposed as a new GABAergic master brake for dopamine systems (Bourdy and Barrot, 2012).

The tVTA/RMTg expresses markers that distinguish it from surrounding regions. It includes high levels of the GABAsynthesizing enzyme GAD 67 (Perrotti et al., 2005; Olson and Nestler, 2007; Jhou et al., 2009a; Kaufling et al., 2009, 2010a), high levels of the $\mu$-opioid receptor immunoreactivity (Jhou et al., 2009a, 2012; Jalabert et al., 2011), a prominent pattern of psychostimulant-induced Fos-related proteins (Scammell et al., 2000; Perrotti et al., 2005; Geisler et al., 2008; Jhou et al., 2009a; 


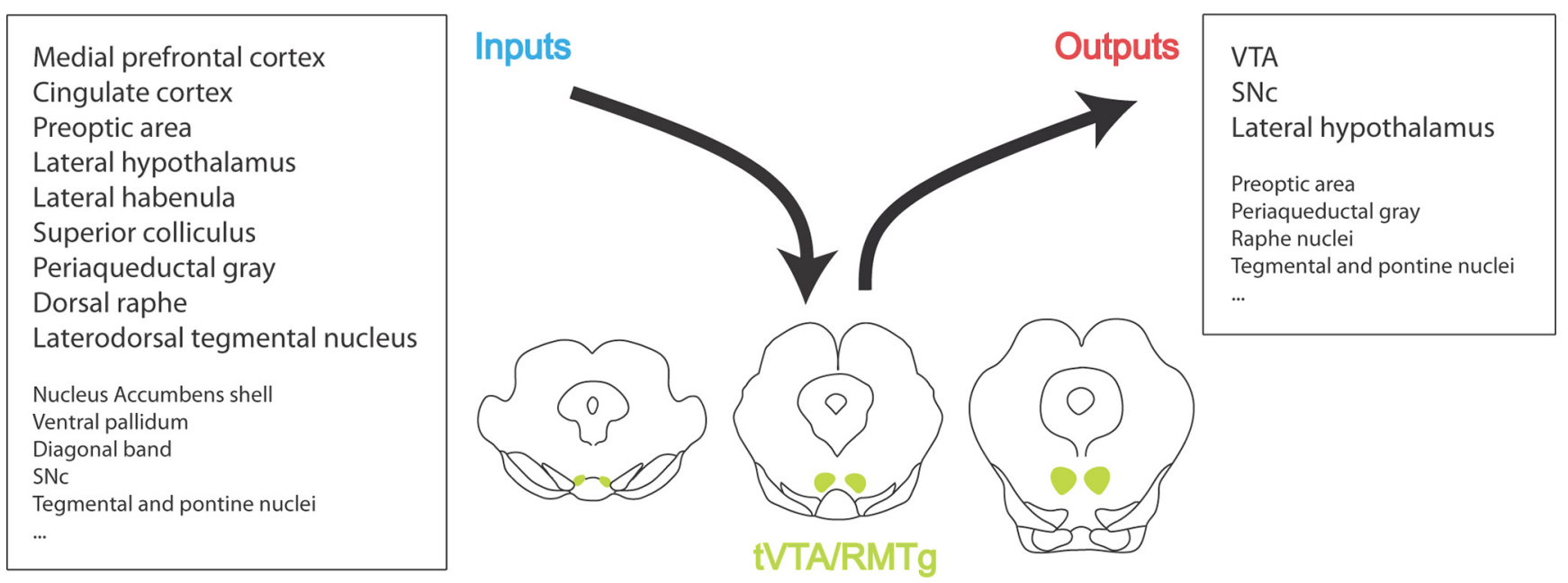

Figure 1. The tVTA/RMTg. The schema represents the rat tVTA/RMTg (in green) and lists its main afferent and efferent connections. Most afferent structures also innervate the VTA directly.

Kaufling et al., 2009, 2010b), and high levels of the neuropeptide nociceptin (Jhou et al., 2012).

In this review, we present some recent and ongoing work on the tVTA/RMTg and its links with dopamine systems.

\section{Psychostimulants, aversive stimuli, and motor inhibition}

Recent research on the tVTA/RMTg started from observations related to psychostimulant induction of FosB/ $\Delta$ FosB (Perrotti et al., 2005) and to the control of aversive responses (Jhou, 2005). The rat $\mathrm{tVTA} / \mathrm{RMTg}$ showed a neuroanatomically delimited increase in the expression of Fos-related proteins following exposure to psychostimulants (Scammell et al., 2000; Perrotti et al., 2005; Geisler et al., 2008; Jhou et al., 2009a; Kaufling et al., 2009, 2010a, 2010b; Rotllant et al., 2010; Zahm et al., 2010; Cornish et al., 2012). This induction was observed with both acute and chronic exposure to psychostimulants, and with both selfadministration and noncontingent administration. There is a strong selectivity of this molecular response, as the Fos-related induction was never observed with non-psychostimulant drugs (Perrotti et al., 2005; Kaufling et al., 2010b).

Changes in tVTA/RMTg neuron firing rates and/or cFos expression were also observed after some negative affective stimuli, such as footshocks, shock-predictive cues, omission of expected rewards, or food deprivation. Conversely, rewards and rewardpredictive cues predominantly inhibited tVTA/RMTg firing (Jhou et al., 2009; Hong et al., 2011), a pattern inverse to that of most dopamine neurons (Schultz, 1998). Dopamine cells are implicated in many aspects of motivated behavior, including motor performance, cognition, affect, and learning, and the tVTA/ RMTg may be implicated in a similarly wide range of functions. Fiber-sparing tVTA/RMTg lesions strikingly attenuated at least three distinct fear- and anxiety-related behaviors: conditioned freezing, unconditioned freezing, and open arm avoidance (Jhou et al., 2009b), suggesting a broad role in aversive behaviors, particularly those involving behavioral inhibition. The three altered behaviors may be triggered through distinct afferents to the tVTA/RMTg (for discussion, see Jhou et al., 2009b). Other behavioral aspects are being investigated, including a possible role for the tVTA/RMTg in the aversive properties of cocaine (Jhou et al., 2010).

The influence that the tVTA/RMTg exerts on behavior is likely related, at least in part, to the influence that this newly defined brain region exerts on dopamine systems.

\section{The tVTA/RMTg and dopamine systems}

The substantia nigra zona compacta (SNc) and VTA receive inhibitory inputs from multiple basal ganglia and basal forebrain regions (Somogyi et al., 1981; Bolam and Smith, 1990; Gonzales and Chesselet, 1990; Smith and Bolam, 1990; Fallon and Loughlin, 1995; Charara et al., 1996; Geisler and Zahm, 2005). SNc and VTA dopamine cells also receive inhibitory synapses from neighboring GABA neurons (Omelchenko and Sesack, 2009). Until recently, the potential inhibitory influence of the tVTA/RMTg on dopamine cells was unrecognized. Light microscopic observations, however, indicated that this projection was among the densest of afferents to the ventral midbrain and literally outlined the position of dopamine neurons (Ferreira et al., 2008; Jhou et al., 2009a; Kaufling et al., 2010a). Moreover, tVTA/RMTg axon varicosities formed multiple close appositions to the soma and dendrites of dopamine cells immunolabeled for the synthetic enzyme tyrosine hydroxylase (TH) (Jhou et al., 2009b; Kaufling et al., 2010a). These results suggested that dopamine neurons were the principal targets of tVTA/RMTg efferents.

To test this hypothesis, ultrastructural analysis was performed on tissue labeled by anterograde tract tracing from the tVTA/ RMTg, and dual immunocytochemistry for tracer and either TH or GABA, in alternate sections. Within the VTA, $\sim 83 \%$ of the synapses formed by tVTA/RMTg axons were onto dendrites immunoreactive for TH (Balcita-Pedicino et al., 2011). Despite the impression formed from light microscopic studies, no axosomatic synapses were found. Using postembedding immunogold, which is more sensitive than pre-embedding for the detection of GABA in axons, all tVTA/RMTg axons were found to be immunoreactive for GABA (Balcita-Pedicino et al., 2011). This finding was consistent with reports that the tVTA/RMTg represents a relatively pure GABAergic cell population (Perrotti et al., 2005; Olson et al., 2007; Jhou et al., 2009a,b; Kaufling et al., 2009, 2010a).

The remaining $17 \%$ of $\mathrm{tVTA} / \mathrm{RMTg}$ synapses within the VTA were onto dendrites containing no TH signal detectable by the pre-embedding immunogold procedure used (Balcita-Pedicino et al., 2011). This finding suggests that some tVTA/RMTg axons contact non-dopamine neurons in the VTA, most of which are GABAergic (Nair-Roberts et al., 2008). This hypothesis is currently being investigated using pre-embedding immunogold, which is more sensitive than postembedding for detecting GABA in dendrites. To date, only a few tVTA/RMTg axons synapsing 


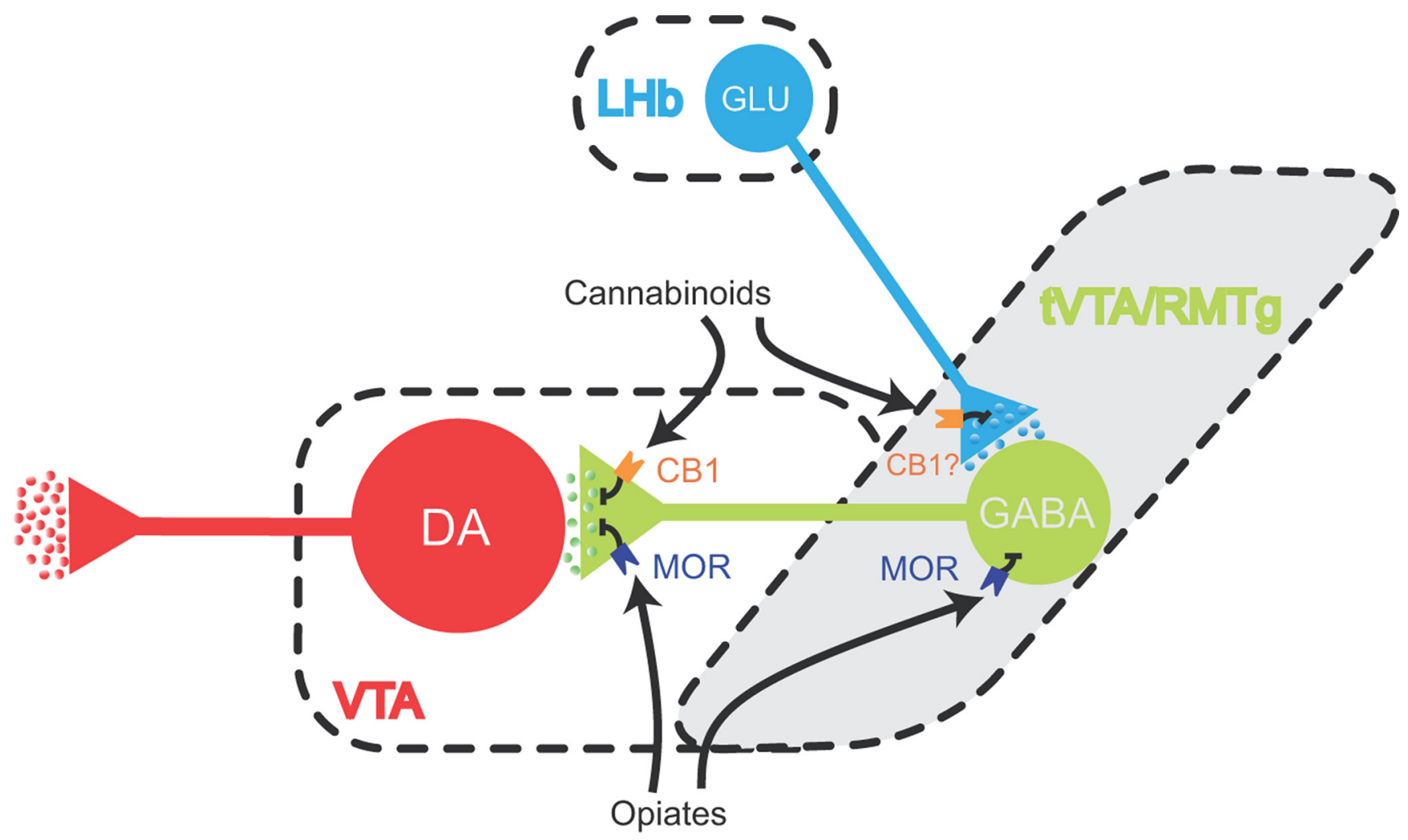

Figure 2. The tVTA/RMTg as a GABA brake for the dopamine system. The schema represents the tVTA/RMTg, its main glutamatergic input (lateral habenula, LHb), and its output to the nearby dopamine systems. Opiates and cannabinoids would recruit dopamine cells (DA) by blocking the GABA brake exerted by neurons of the tVTA/RMTg onto dopamine cells. CB1, cannabinoid receptors $1 ; \mathrm{MOR}, \mu$-Opioid receptors.

onto GABA dendrites have been detected; additional sampling is needed to confirm these results. Such an outcome might indicate that the tVTA/RMTg also contacts glutamate-containing VTA neurons (Yamaguchi et al., 2007; Nair-Roberts et al., 2008). Alternatively, prior results may have included false-negative outcomes reflecting insufficient detection of low levels of TH. These possibilities are presently being examined.

Electron microscopy is now also being used to examine the tVTA/RMTg projection to the SNc. Although the findings are preliminary, all of the tVTA/RMTg axons observed to date synapse onto dendrites immunolabeled for $\mathrm{TH}$ and not onto unlabeled dendrites. Given that most SNc neurons are dopaminergic (González-Hernández and Rodríguez, 2000), this finding is not unexpected. Further investigation will include the dorsal portion of the SN reticulata, in particular the cell "bridges" where dopamine and non-dopamine cells intermingle. In this zone, it is possible that tVTA/RMTg axons will synapse onto non-dopamine neurons, although the density of this input is weak (Jhou et al., 2009b).

Collectively, these findings indicate that a substantial GABAergic projection from the tVTA/RMTg primarily targets dopamine neurons in the SNc and VTA. The placement of these synapses is mainly onto intermediate and proximal dendrites, and less commonly onto distal dendrites. The density of these synapses and their relatively proximal placement suggests that the tVTA/RMTg mediates a strong inhibitory influence on dopamine neurons throughout the ventral midbrain.

Dopamine systems are subject to an accelerator/brake control of their activity (Carlsson et al., 2001), which is critical for finely shaping dopamine responses. In agreement with neuroanatomical evidence, electrophysiological studies confirmed that the
tVTA-RMTg constitutes a major brake for dopamine systems: the inhibition of tVTA increases dopamine cell activity (Jalabert et al., 2011), and the stimulation of tVTA decreases it (Hong et al., 2011; Lecca et al., 2011, 2012; Matsui and Williams, 2011). Close attention was thus given to the tVTA/RMTg involvement in responses to drugs of abuse, more particularly opiates and cannabinoids, as well as in the processing of prediction error.

\section{The tVTA/RMTg and opiates}

Morphine is a potent opiate analgesic with a high addictive potential in some specific contexts outside medical usage (Shurman et al., 2010). A broadly accepted circuit model for morphine action on dopamine neurons suggests that morphine excites VTAdopamine neurons by a disinhibitory mechanism involving neighboring GABA cells (Johnson and North, 1992). However, recent electrophysiological evidence has challenged this canonical model, by proposing an alternative inhibitory source, the tVTA/RMTg, for the excitatory effect of morphine on VTAdopamine neurons (Fig. 2) (Jalabert et al., 2011; Lecca et al., 2011, 2012; Matsui and Williams, 2011; Bourdy and Barrot, 2012). Indeed, tVTA/RMTg cells express high levels of $\mu$-opioid receptors (Jhou et al., 2009a, 2012; Jalabert et al., 2011), and in vivo, ex vivo, and optogenetic electrophysiological approaches demonstrated that morphine excites dopamine neurons by targeting receptors localized to tVTA/RMTg cell bodies as well as its terminals within the VTA (Jalabert et al., 2011; Lecca et al., 2011; Matsui and Williams, 2011; Lecca et al., 2012).

Exploring the sources of inhibitory and excitatory drives onto dopamine neurons is critical for understanding the impact of network activity on the integrative properties of dopamine neurons in response to morphine. In addition to potent tonic GABA 
modulation (Paladini and Tepper, 1999), VTA-dopamine neurons receive glutamatergic inputs from diverse brain nuclei (Geisler et al., 2007; Dobi et al., 2010). Evidence indicates a critical role for VTA glutamate receptors in morphine rewarding properties (Carlezon et al., 1997; Harris et al., 2004), and the crucial role of the inhibition/excitation balance for the in vivo effects of morphine on dopamine neurons has recently been demonstrated (Jalabert et al., 2011). The influence of tVTA/RMTg in morphine-induced activation of VTA-dopamine neurons was assessed by intra-VTA infusion of morphine after selective inactivation of the tVTA/RMTg (Jalabert et al., 2011). In this condition, morphine failed to increase dopamine activity, which demonstrated that tVTA/RMTg tonic activity was necessary for morphine-induced responses of VTA-dopamine neurons. These in vivo results were confirmed ex vivo by a study demonstrating that GABA projections from the tVTA/RMTg were inhibited by opioids, which consequently disinhibited VTA-dopamine neurons (Matsui and Williams, 2011). However, this GABA-related disinhibition did not preclude a role for VTA glutamatergic transmission in the morphine effect. Indeed, blocking VTA NMDA and AMPA receptors prevented morphine-induced excitation of VTA-dopamine neurons (Jalabert et al., 2011). This outcome showed that VTA glutamatergic transmission is necessary for the in vivo excitatory effect of morphine.

These recent findings were extended by assessing the functional consequences of increasing the excitatory control of VTAdopamine neurons on morphine-induced responses ( $\mathrm{M}$. Jalabert, C. Glangetas, L. Groc, and F. Georges, unpublished data). Based on previous ex vivo electrophysiological studies (Ungless et al., 2001), the VTA was assessed $24 \mathrm{~h}$ following a single acute cocaine injection. The results established that cocaine experience potentiates morphine-induced excitation of VTAdopamine neurons in vivo, suggesting that the intrinsic excitability of VTA-dopamine neurons may be important for scaling morphine responses. Given that morphine has a high addictive potential in specific situations (Shurman et al., 2010), it would be important to assess whether the excitatory context of dopamine neurons may tune the addictive potency of morphine.

The critical role of the tVTA/RMTg in opiate action is also supported by behavioral data. The injection of a $\mu$-opioid receptor agonist into the tVTA/RMTg markedly reduced pain responses to subcutaneous formalin injections (Jhou et al., 2012), and infusions of $\mu$-opioid agonists or GABA agonists into the tVTA/RMTg supported self-administration and conditioned place preference (Jhou et al., 2012). These data suggest that tVTA/ RMTg inhibition can be reinforcing. Conversely, activation of the tVTA/RMTg - as obtained through optogenetic stimulation of afferents from the lateral habenula- has been shown to promote behavioral avoidance (Stamatakis and Stuber, 2012).

Interestingly, some functional properties recently attributed to the tVTA/RMTg have also been ascribed to VTA GABAergic neurons (Cohen et al., 2012; Tan et al., 2012; van Zessen et al., 2012), raising questions about whether these two populations are similar or separate. The insertion of the rostral part of the tVTA/ RMTg within areas that are designated in brain atlases as VTA may add to the confusion. While most studies have not attempted to distinguish the tVTA/RMTg from nearby sites, some studies do show substantial differences. Anatomically, VTA GABA neurons exhibit prominent projections to the forebrain (Van Bockstaele and Pickel, 1995; Carr and Sesack, 2000a, 2000b) that the tVTA/RMTg lacks (Jhou et al., 2009a; Kaufling et al., 2010b). Conversely, the tVTA/RMTg receives an intense lateral habenula synaptic input that is several-fold greater than the habenular pro- jection to the VTA (Balcita-Pedicino et al., 2011). Even more critically, injections of small (nanomolar) quantities of $\mu$-opioid receptor agonist or GABA agonist that produced reinforcement or analgesia in the tVTA/RMTg did not produce these effects when injected into the VTA (Jhou et al., 2012). This may seem surprising considering the prior reports of reward or analgesia after larger intra-VTA injections of $\mu$-opioid receptor agonists (Morgan and Franklin, 1991; Nader and van der Kooy, 1997; Zangen et al., 2002), and considering that opiates can act directly on tVTA/RMTg terminals within the VTA to recruit dopamine neurons (Jalabert et al., 2011; Matsui and Williams, 2011). However, very small injections strongly limit the drug spread, affecting a restricted part of the considered structure. Such small injections into the VTA might affect a subset of cells or terminals only, which may not be enough to elicit detectable behavioral consequences. On the other hand, tVTA/RMTg injections would target GABA cells with widespread projection fields into the VTA (Jhou et al., 2009a; Kaufling et al., 2010), which may result in the secondary disinhibition of a much larger population of dopamine cells. These results and the partial inclusion of the tVTA/ RMTg within the posterior aspects of VTA also raise the possibility that some of the behavioral data from the last decade showing antero-posterior differences in the behavioral influence of the VTA might be related to tVTA/RMTg targeting (Ikemoto et al., 1998, 2006; Zangen et al., 2002, 2006; Rodd et al., 2004, 2008; Shabat-Simon et al., 2008; Linsenbardt and Boehm, 2009; Hauser et al., 2011). This question may be particularly relevant concerning the action of opiates, ethanol, and cannabinoids.

\section{The tVTA/RMTg and cannabinoids}

Not only opiates, but cannabinoids also are known to activate dopamine neurons by disinhibition (Lüscher and Ungless, 2006), i.e., by depressing GABA release and therefore shifting the balance between excitatory and inhibitory inputs impinging on dopamine cells (Marinelli et al., 2006; Lobb et al., 2010; Morikawa and Paladini, 2011). As mentioned above, the tVTA/RMTg, as a major source of GABA in the VTA, powerfully contributes to this balance. Hence, the strength of tVTA/RMTg-induced inhibition of dopamine cells was correlated with their spontaneous discharge rate (Lecca et al., 2012), and inactivation of the tVTA/ RMTg increased the firing rate of dopamine neurons (Jalabert et al., 2011). The recent characterization of tVTA/RMTg neurons also sheds new light onto the mechanisms by which cannabinoids excite dopamine neurons (Fig. 2). Indeed, these drugs depress tVTA/RMTg neurons' activity and strongly reduce the inhibition exerted by tVTA/RMTg afferents (Lecca et al., 2011, 2012). Patch clamp experiments also showed that the cannabinoid agonist WIN55212-2 depressed IPSCs evoked in VTA dopamine cells by stimulation of tVTA/RMTg afferents through a presynaptic mechanism (Lecca et al., 2012), suggesting that tVTA/RMTg terminals express cannabinoid receptors 1 (CB1).

The endocannabinoid system plays a major role in mechanisms of addiction: CB1 agonists promoted reinstatement of extinguished drug-seeking behavior (the equivalent of relapse in humans) for a number of drugs of abuse (Fattore et al., 2003, 2005; López-Moreno et al., 2004; Spano et al., 2004; McGregor et al., 2005; Justinova et al., 2008; Gamaleddin et al., 2012). Conversely, CB1 antagonists (i.e., rimonabant) reduced the rewarding effects of most drugs of abuse (Colombo et al., 1998; De Vries et al., 2001; Navarro et al., 2001; Cohen et al., 2002; Rigotti et al., 2009). However, rimonabant was withdrawn from the market for increased risk of depression and suicide (Christensen et al., 2007). From this lesson, we learned that CB1 receptor blockade 
A
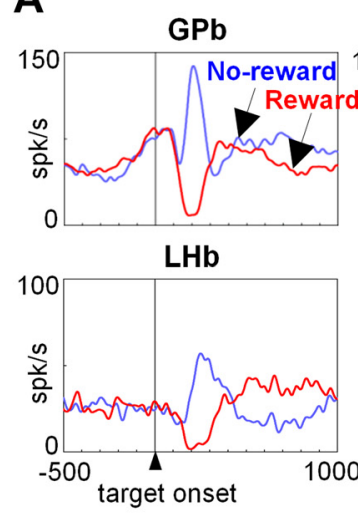

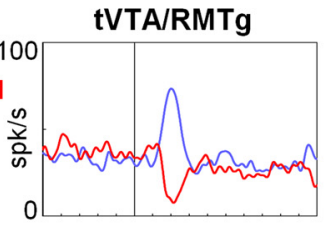

DA

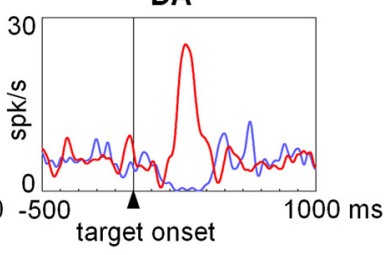

B

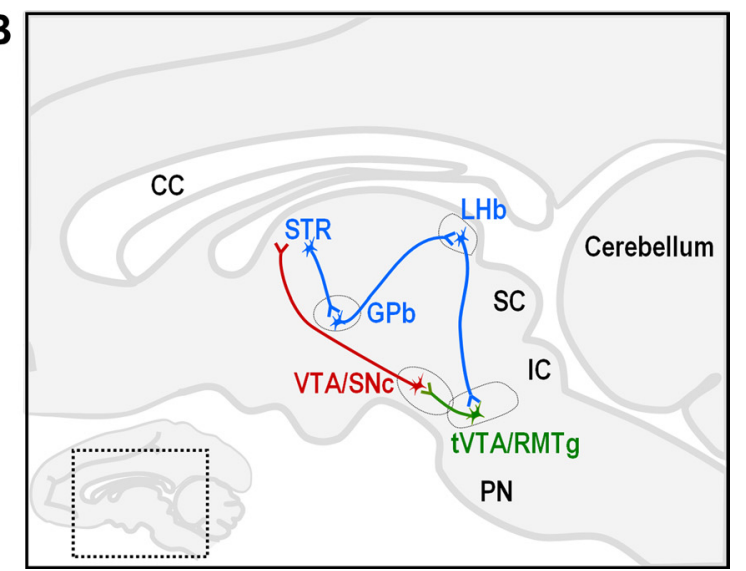

Figure 3. The tVTA/RMTg as part of the reward prediction error circuit. $A$, Responses of representative GPb, lateral habenula (LHb), tVTA/RMTg, and dopamine neurons (DA) to the visual target onset in the 1DR task (Hong et al., 2011). The averaged activity of each neuron, expressed as a spike (spk) density function, is shown separately for the reward trials (red) and no-reward trials (blue) as the response to the onset of the target. $\boldsymbol{B}$, Neuroanatomical schematic of the reward prediction error circuit in the monkey. CC, Corpus callosum; GPb, borders of the globus pallidus internal segment; IC, inferior colliculus; PN, pontine nuclei; SC, superior colliculus; STR, striatum.

decreases the motivation to seek sources of reward, including natural ones (Horder et al., 2010) and induces states of anhedonia and enhanced sensitivity to aversive stimuli or punishment, which might lead vulnerable individuals to depression.

The tVTA/RMTg is in the ideal position, being a possible hub between aversion- and reward-responding brain regions, to function as a switch between opposite motivational states and to relay information to dopamine neurons (Lavezzi and Zahm, 2011; Bourdy and Barrot, 2012). Under these circumstances, the tVTA/RMTg terminals on VTA cells might be targets for endocannabinoid-mediated short- and long-term forms of synaptic plasticity. Electrophysiological evidence supports this hypothesis and indicates that endocannabinoids regulate the strength of these afferents and ultimately adjust dopamine neuron firing (Pistis et al., unpublished data). Hence, by decreasing GABA release from tVTA/RMTg terminals, the endocannabinoids might sensitize dopamine neurons toward excitatory inputs evoked by rewarding stimuli, such as those associated with drugs of abuse. This might result in enhanced firing activity and dopamine release in terminal regions (Melis and Pistis, 2012; Melis et al., 2012), and possibly behavioral sensitization or reinstatement of drug-taking behavior. Conversely, deficits in the endocannabinoid tone on tVTA/RMTg synapses are expected to promote GABA release and depress dopamine cell firing. This enhanced inhibitory control on dopamine neurons might dampen their responses to natural rewards or addicting drugs, or increase those toward aversive stimuli, ultimately leading to reduced motivation or to maladaptive responses to aversion and punishment.

This hypothetical mechanism could also bear relevance for gender- or strain-specific vulnerability to addictive drugs. It is noteworthy that the appetitive properties of addicting drugs result from activation of brain reward pathways and suppression of responses in neural circuits mediating aversion (Riley, 2011). Individuals susceptible to addiction might experience reduced responses to the aversive component intrinsic to several addictive drugs, such as alcohol (Rezvani et al., 2010) and cannabinoids (Quinn et al., 2008), or to negative consequences of compulsive drug intake (Riley, 2011). In this regard, experiments in alcoholpreferring rat strains or in female rats-more vulnerable than male counterparts to cannabinoid self-administration (Fattore and Fratta, 2010) - may provide information on the strength of
tVTA/RMTg afferents and of endocannabinoid-mediated synaptic depression, and on how these parameters may correlate with the vulnerability to addiction. These hypotheses concerning the endocannabinoid system and tVTA/RMTg function are presently under investigation.

\section{Placing tVTA/RMTg into prediction error pathways}

The above-mentioned properties of the tVTA/RMTg suggest roles in a variety of motivational processes, consistent with emerging evidence placing it in a critical location among the pathways processing reward prediction errors (RPEs). Neurons from the lateral habenula in the monkey are excited by a visual stimulus that indicates the absence of reward and inhibited by a stimulus that indicates the presence of reward (Matsumoto and Hikosaka, 2007). This negative reward signal contributes to the well known reward coding of dopamine neurons (Christoph et al., 1986; Matsumoto and Hikosaka, 2007). The suggestion that the RPE signal in dopamine neurons may come from the lateral habenula triggered research to examine the neural elements of reinforcement learning connected to the lateral habenula and dopamine areas (Fig. 3A). It was hypothesized that the globus pallidus internal segment (GPi) could play a critical role, considering the fact that the major input to the lateral habenula comes from the GPi (Parent et al., 2001). To test this hypothesis, antidromic stimulation was used to identify GPi neurons that projected to the lateral habenula, in combination with a behavioral saccade task known as the onedirection-rewarded (1DR) to control the level of motivation. The results showed that lateral habenula-projecting neurons were located mainly along the borders of the $\mathrm{GPi}(\mathrm{GPb})$ and displayed firing patterns different from movement-related GPi neurons. A majority of GPb neurons encoded a negative RPE similar to that observed for lateral habenula cells, while some other neurons encoded a positive RPE. A detailed analysis showed that only the negative-RPE-coding neurons discriminated the reward/no reward meaning of the saccade target earlier than the lateral habenula. These results led to the suggestion that the GPb-to-lateral habenula projection was excitatory (Hong and Hikosaka, 2008a). Consistent with this idea, the electrical stimulation of the $\mathrm{GPb}$ triggered a short-latency excitatory response in lateral habenula neurons (Hong and Hikosaka, 2008b).

While the suppressive influence of the lateral habenula on the dopamine system was established, a more detailed circuit hypothesis emerged in the following years from several laboratories. 
It was suggested that a little-known structure, the tVTA/RMTg, receives lateral habenula inputs and projects to dopamine neurons in rodents (Jhou et al., 2009a,b; Kaufling et al., 2009, 2010; Omelchenko et al., 2009; Balcita-Pedicino et al., 2011). To determine the function of this suggested circuit, antidromic and orthodromic recording techniques were used between the lateral habenula, tVTA/RMTg, and dopamine areas, in combination with injection of a retrograde tracer into the dopamine cell area in the monkey. Antidromically and orthodromically activated neurons were recorded while the monkey was performing the $1 \mathrm{DR}$ task. Results showed that tVTA/RMTg neurons were localized in the paramedian tegmental area, caudal to the VTA, extending caudally toward the pedunculopontine tegmental nucleus along the lower border of the superior cerebellar peduncle decussation (Hong et al., 2011). Physiologically, those neurons receiving inputs from the lateral habenula showed a similar activation pattern to lateral habenula neurons (Fig. $3 B$ ) and sent their suppressive signals to dopamine cells. In addition, many tVTA/ RMTg neurons showed tonic responses resembling the "state value" signals in the dorsal raphe (Bromberg-Martin et al., 2010), which is one of the targets of the tVTA/RMTg. Interestingly, about half of the tVTA/RMTg neurons discriminated the reward/no reward conditions earlier than the lateral habenula, suggesting that the tVTA/RMTg may receive some reward-related inputs originating from areas other than the lateral habenula.

These results support the hypothesis that the negative RPE signal of the lateral habenula originates from the basal ganglia and is sent to the tVTA/RMTg. The tVTA/RMTg in turn translates this negative RPE into a dopamine-positive RPE, while transmitting additional motivational signals to non-dopamine networks, therefore reinforcing rewarding actions and discouraging actions leading to failure. This hypothesis gains support from a recent study in mice showing that stimulation of lateral habenula inputs to the tVTA/RMTg is sufficient to induce behavioral avoidance (Stamatakis and Stuber, 2012). This observation suggests that the circuit outlined above represents a shared mechanism across species.

\section{Concluding remarks}

The elucidation of a new brain region is a relatively rare event in the present age of neuroscience. Such discoveries have the potential to rapidly advance our knowledge, as evidenced by the speed with which new data have emerged regarding the tVTA/RMTg and as evidenced by the importance of these revelations for understanding the functional operation of reward and aversion systems. The tVTA/RMTg has proved itself to be a major source of inhibitory regulation of SNc and VTA dopamine neurons whose substantial influence was missing from previous models of reinforcement learning. This brainstem region and its ascending projections serve as substrates for activation of dopamine cells by different drugs of abuse, thus contributing to their rewarding and/or aversive properties. Furthermore, the tVTA/RMTg provides a key node in the circuitry by which dopamine neurons acquire information predictive of reward and punishment. Because of these essential roles, it is possible that dysfunction of the tVTA/RMTg contributes to the pathophysiology of mental disorders such as major depression and addiction. Moreover, the tVTA/RMTg may serve as a potentially useful site for therapeutic intervention in these conditions. It is hoped that what is learned in the next few years through advanced study of this critical brain structure illuminates understanding of how regulatory systems control motivated behavior.

\section{References}

Balcita-Pedicino JJ, Omelchenko N, Bell R, Sesack SR (2011) The inhibitory influence of the lateral habenula on midbrain dopamine cells: ultrastructural evidence for indirect mediation via the rostromedial mesopontine tegmental nucleus. J Comp Neurol 519:1143-1164. CrossRef Medline

Barrot M, Thome J (2011) Discovering a new anatomical structure in the brain: implications for neuropsychiatry and therapy. World J Biol Psychiatry 12 [Suppl 1]:19-22. CrossRef

Bolam JP, Smith Y (1990) The GABA and substance P input to dopaminergic neurones in the substantia nigra of the rat. Brain Res 529:57-78. CrossRef Medline

Bourdy R, Barrot M (2012) A new control for dopaminergic systems: pulling the VTA by the tail. Trends Neurosci. Advance online publication. Retrieved August 29, 2012. doi:org/10.1016/j.tins.2012.06.007. CrossRef Medline

Bromberg-Martin ES, Hikosaka O, Nakamura K (2010) Coding of task reward value in the dorsal raphe nucleus. J Neurosci 30:6262-6272. CrossRef Medline

Carlezon WA Jr, Boundy VA, Haile CN, Lane SB, Kalb RG, Neve RL, Nestler EJ (1997) Sensitization to morphine induced by viral-mediated gene transfer. Science 277:812-814. CrossRef Medline

Carlsson A, Waters N, Holm-Waters S, Tedroff J, Nilsson M, Carlsson ML (2001) Interactions between monoamines, glutamate, and GABA in schizophrenia: new evidence. Annu Rev Pharmacol Toxicol 41:237-260. CrossRef Medline

Carr DB, Sesack SR (2000a) Projections from the rat prefrontal cortex to the ventral tegmental area: target specificity in the synaptic associations with mesoaccumbens and mesocortical neurons. J Neurosci 20:3864-3873. Medline

Carr DB, Sesack SR (2000b) GABA-containing neurons in the rat ventral tegmental area project to the prefrontal cortex. Synapse 38:114-123. CrossRef Medline

Charara A, Smith Y, Parent A (1996) Glutamatergic inputs from the pedunculopontine nucleus to midbrain dopaminergic neurons in primates: Phaseolus vulgaris-leucoagglutinin anterograde labeling combined with postembedding glutamate and GABA immunohistochemistry. J Comp Neurol 364:254-266. CrossRef Medline

Christensen R, Kristensen PK, Bartels EM, Bliddal H, Astrup A (2007) Efficacy and safety of the weight-loss drug rimonabant: a meta-analysis of randomised trials. Lancet 370:1706-1713. CrossRef Medline

Christoph GR, Leonzio RJ, Wilcox KS (1986) Stimulation of the lateral habenula inhibits dopamine-containing neurons in the substantia nigra and ventral tegmental area of the rat. J Neurosci 6:613-619. Medline

Cohen C, Perrault G, Voltz C, Steinberg R, Soubrié P (2002) SR141716, a central cannabinoid $(\mathrm{CB}(1))$ receptor antagonist, blocks the motivational and dopamine-releasing effects of nicotine in rats. Behav Pharmacol 13: 451-463. CrossRef Medline

Cohen JY, Haesler S, Vong L, Lowell BB, Uchida N (2012) Neuron-typespecific signals for reward and punishment in the ventral tegmental area. Nature 482:85-88. CrossRef Medline

Colombo G, Agabio R, Fà M, Guano L, Lobina C, Loche A, Reali R, Gessa GL (1998) Reduction of voluntary ethanol intake in ethanol-preferring sP rats by the cannabinoid antagonist SR-141716. Alcohol Alcohol 33:126130. Medline

Cornish JL, Hunt GE, Robins L, McGregor IS (2012) Regional c-Fos and FosB/DeltaFosB expression associated with chronic methamphetamine self-administration and methamphetamine-seeking behavior in rats. Neuroscience 206:100-114. CrossRef Medline

De Vries TJ, Shaham Y, Homberg JR, Crombag H, Schuurman K, Dieben J, Vanderschuren LJ, Schoffelmeer AN (2001) A cannabinoid mechanism in relapse to cocaine seeking. Nat Med 7:1151-1154. CrossRef Medline

Dobi A, Margolis EB, Wang HL, Harvey BK, Morales M (2010) Glutamatergic and nonglutamatergic neurons of the ventral tegmental area establish local synaptic contacts with dopaminergic and nondopaminergic neurons. J Neurosci 30:218-229. CrossRef Medline

Fallon JH, Loughlin SE (1995) Substantia nigra. In: The rat nervous system, Ed 2 (Paxinos G, ed), pp 215-237. San Diego: Academic.

Fattore L, Fratta W (2010) How important are sex differences in cannabinoid action? Br J Pharmacol 160:544-548. CrossRef Medline

Fattore L, Spano MS, Cossu G, Deiana S, Fratta W (2003) Cannabinoid mechanism in reinstatement of heroin-seeking after a long period of abstinence in rats. Eur J Neurosci 17:1723-1726. CrossRef Medline 
Fattore L, Deiana S, Spano SM, Cossu G, Fadda P, Scherma M, Fratta W (2005) Endocannabinoid system and opioid addiction: behavioural aspects. Pharmacol Biochem Behav 81:343-359. CrossRef Medline

Ferreira JG, Del-Fava F, Hasue RH, Shammah-Lagnado SJ (2008) Organization of ventral tegmental area projections to the ventral tegmental areanigral complex in the rat. Neuroscience 153:196-213. CrossRef Medline

Gamaleddin I, Wertheim C, Zhu AZ, Coen KM, Vemuri K, Makryannis A, Goldberg SR, Le Foll B (2012) Cannabinoid receptor stimulation increases motivation for nicotine and nicotine seeking. Addict Biol 17:4761. CrossRef Medline

Geisler S, Zahm DS (2005) Afferents of the ventral tegmental area in the rat-anatomical substratum for integrative functions. J Comp Neurol 490: 270-294. CrossRef Medline

Geisler S, Derst C, Veh RW, Zahm DS (2007) Glutamatergic afferents of the ventral tegmental area in the rat. J Neurosci 27:5730-5743. CrossRef Medline

Geisler S, Marinelli M, Degarmo B, Becker ML, Freiman AJ, Beales M, Meredith GE, Zahm DS (2008) Prominent activation of brainstem and pallidal afferents of the ventral tegmental area by cocaine. Neuropsychopharmacology 33:2688-2700. CrossRef Medline

Gonçalves L, Sego C, Metzger M (2012) Differential projections from the lateral habenula to the rostromedial tegmental nucleus and ventral tegmental area in the rat. J Comp Neurol 520:1278-1300. CrossRef Medline

Gonzales C, Chesselet MF (1990) Amygdalonigral pathway: an anterograde study in the rat with Phaseolus vulgaris leucoagglutinin (PHA-L). J Comp Neurol 297:182-200. CrossRef Medline

González-Hernández T, Rodríguez M (2000) Compartmental organization and chemical profile of dopaminergic and GABAergic neurons in the substantia nigra of the rat. J Comp Neurol 421:107-135. CrossRef Medline

Harris GC, Wimmer M, Byrne R, Aston-Jones G (2004) Glutamate-associated plasticity in the ventral tegmental area is necessary for conditioning environmental stimuli with morphine. Neuroscience 129:841-847. CrossRef Medline

Hauser SR, Ding ZM, Getachew B, Toalston JE, Oster SM, McBride WJ, Rodd ZA (2011) The posterior ventral tegmental area mediates alcoholseeking behavior in alcohol-preferring rats. J Pharmacol Exp Ther 336: 857-865. CrossRef Medline

Herkenham M, Nauta WJ (1979) Efferent connections of the habenular nuclei in the rat. J Comp Neurol 187:19-47. CrossRef Medline

Hong S, Hikosaka O (2008a) The globus pallidus sends reward-related signals to the lateral habenula. Neuron 60:720-729. CrossRef Medline

Hong S, Hikosaka O (2008b) Convergent inputs from the ventral striatum and the dorsal striatum to the lateral habenula in the monkey. Soc Neurosci Abstr 34:578.6.

Hong S, Jhou TC, Smith M, Saleem KS, Hikosaka O (2011) Negative reward signals from the lateral habenula to dopamine neurons are mediated by rostromedial tegmental nucleus in primates. J Neurosci 31:11457-11471. CrossRef Medline

Horder J, Harmer CJ, Cowen PJ, McCabe C (2010) Reduced neural response to reward following 7 days treatment with the cannabinoid CB1 antagonist rimonabant in healthy volunteers. Int J Neuropsychopharmacol 13:1103-1113. CrossRef Medline

Ikemoto S (2007) Dopamine reward circuitry: two projection systems from the ventral midbrain to the nucleus accumbens-olfactory tubercle complex. Brain Res Rev 56:27-78. CrossRef Medline

Ikemoto S, Murphy JM, McBride WJ (1998) Regional differences within the rat ventral tegmental area for muscimol self-infusions. Pharmacol Biochem Behav 61:87-92. CrossRef Medline

Ikemoto S, Qin M, Liu ZH (2006) Primary reinforcing effects of nicotine are triggered from multiple regions both inside and outside the ventral tegmental area. J Neurosci 26:723-730. CrossRef Medline

Jalabert M, Bourdy R, Courtin J, Veinante P, Manzoni OJ, Barrot M, Georges F (2011) Neuronal circuits underlying acute morphine action on dopamine neurons. Proc Natl Acad Sci U S A 108:16446-16450. CrossRef Medline

Jhou T (2005) Neural mechanisms of freezing and passive aversive behaviors. J Comp Neurol 493:111-114. CrossRef Medline

Jhou TC, Geisler S, Marinelli M, Degarmo BA, Zahm DS (2009a) The mesopontine rostromedial tegmental nucleus: a structure targeted by the lateral habenula that projects to the ventral tegmental area of Tsai and substantia nigra compacta. J Comp Neurol 513:566-596. CrossRef Medline

Jhou TC, Fields HL, Baxter MG, Saper CB, Holland PC (2009b) The rostromedial tegmental nucleus (RMTg), a GABAergic afferent to midbrain dopamine neurons, encodes aversive stimuli and inhibits motor responses. Neuron 61:786-800. CrossRef Medline

Jhou TC, Good C, Xu SP, Lupica C, Ikemoto S (2010) Biphasic responses of lateral habenula neurons to cocaine: implications for opponent processes. Soc Neurosci Abstr 36:707.726.

Jhou TC, Xu SP, Lee MR, Gallen CL, Ikemoto S (2012) Mapping of reinforcing and analgesic effects of the mu opioid agonist Endomorphin-1 in the ventral midbrain of the rat. Psychopharmacology. Advance online publication. Retrieved August 29, 2012. CrossRef Medline

Johnson SW, North RA (1992) Opioids excite dopamine neurons by hyperpolarization of local interneurons. J Neurosci 12:483-488. Medline

Justinova Z, Munzar P, Panlilio LV, Yasar S, Redhi GH, Tanda G, Goldberg SR (2008) Blockade of THC-seeking behavior and relapse in monkeys by the cannabinoid $\mathrm{CB}(1)$-receptor antagonist rimonabant. Neuropsychopharmacology 33:2870-2877. CrossRef Medline

Kaufling J, Veinante P, Pawlowski SA, Freund-Mercier MJ, Barrot M (2009) Afferents to the GABAergic tail of the ventral tegmental area in the rat. J Comp Neurol 513:597-621. CrossRef Medline

Kaufling J, Veinante P, Pawlowski SA, Freund-Mercier MJ, Barrot M (2010a) Gamma-aminobutyric acid cells with cocaine-induced DeltaFosB in the ventral tegmental area innervate mesolimbic neurons. Biol Psychiat 67: 88-92. CrossRef Medline

Kaufling J, Waltisperger E, Bourdy R, Valera A, Veinante P, Freund-Mercier MJ, Barrot M (2010b) Pharmacological recruitment of the GABAergic tail of the ventral tegmental area by acute drug exposure. Br J Pharmacol 161:1677-1691. CrossRef Medline

Lavezzi HN, Zahm DS (2011) The mesopontine rostromedial tegmental nucleus: an integrative modulator of the reward system. Basal Ganglia 1:191-200. CrossRef Medline

Lecca S, Melis M, Luchicchi A, Ennas MG, Castelli MP, Muntoni AL, Pistis M (2011) Effects of drugs of abuse on putative rostromedial tegmental neurons, inhibitory afferents to midbrain dopamine cells. Neuropsychopharmacology 36:589-602. CrossRef Medline

Lecca S, Melis M, Luchicchi A, Muntoni AL, Pistis M (2012) Inhibitory inputs from rostromedial tegmental neurons regulate spontaneous activity of midbrain dopamine cells and their responses to drugs of abuse. Neuropsychopharmacology 37:1164-1176. CrossRef Medline

Linsenbardt DN, Boehm SL $2^{\text {nd }}$ (2009) Agonism of the endocannabinoid system modulates binge-like alcohol intake in male C57BL/6J mice: involvement of the posterior ventral tegmental area. Neuroscience 164: 424-434. CrossRef Medline

Lobb CJ, Wilson CJ, Paladini CA (2010) A dynamic role for GABA receptors on the firing pattern of midbrain dopaminergic neurons. J Neurophysiol 104:403-413. CrossRef Medline

López-Moreno JA, Gonzalez-Cuevas G, Rodríguez de Fonseca F, Navarro M (2004) Long-lasting increase of alcohol relapse by the cannabinoid receptor agonist WIN 55,212-2 during alcohol deprivation. J Neurosci 24: 8245-8252. CrossRef Medline

Lüscher C, Ungless MA (2006) The mechanistic classification of addictive drugs. PLoS Med 3:e437. CrossRef Medline

Marinelli M, Rudick CN, Hu XT, White FJ (2006) Excitability of dopamine neurons: modulation and physiological consequences. CNS Neurol Disord Drug Targets 5:79-97. CrossRef Medline

Matsui A, Williams JT (2011) Opioid-sensitive GABA inputs from rostromedial tegmental nucleus synapse onto midbrain dopamine neurons. J Neurosci 31:17729-17735. CrossRef Medline

Matsumoto M, Hikosaka O (2007) Lateral habenula as a source of negative reward signals in dopamine neurons. Nature 447:1111-1115. CrossRef Medline

McGregor IS, Dam KD, Mallet PE, Gallate JE (2005) Delta9-THC reinstates beer- and sucrose-seeking behaviour in abstinent rats: comparison with midazolam, food deprivation and predator odour. Alcohol Alcohol 40: 35-45. CrossRef Medline

Melis M, Pistis M (2012) Hub and switches: endocannabinoid signalling in midbrain dopamine neurons. Philos Trans R Soc Lond B Biol Sci, in press.

Melis M, Muntoni AL, Pistis M (2012) Endocannabinoids and the processing of value-related signals. Front Pharmacol 3:7. Medline 
Morgan MJ, Franklin KB (1991) Dopamine receptor subtypes and formalin test analgesia. Pharmacol Biochem Behav 40:317-322. CrossRef Medline

Morikawa H, Paladini CA (2011) Dynamic regulation of midbrain dopamine neuron activity: intrinsic, synaptic, and plasticity mechanisms. Neuroscience 198:95-111. CrossRef Medline

Nader K, van der Kooy D (1997) Deprivation state switches the neurobiological substrates mediating opiate reward in the ventral tegmental area. J Neurosci 17:383-390. Medline

Nair-Roberts RG, Chatelain-Badie SD, Benson E, White-Cooper H, Bolam JP, Ungless MA (2008) Stereological estimates of dopaminergic, GABAergic and glutamatergic neurons in the ventral tegmental area, substantia nigra and retrorubral field in the rat. Neuroscience 152:10241031. CrossRef Medline

Navarro M, Carrera MR, Fratta W, Valverde O, Cossu G, Fattore L, Chowen JA, Gomez R, del Arco I, Villanua MA, Maldonado R, Koob GF, Rodriguez de Fonseca F (2001) Functional interaction between opioid and cannabinoid receptors in drug self-administration. J Neurosci 21:5344-5350. Medline

Olson VG, Nestler EJ (2007) Topographical organization of GABAergic neurons within the ventral tegmental area of the rat. Synapse 61:87-95. CrossRef Medline

Omelchenko N, Sesack SR (2009) Ultrastructural analysis of local collaterals of rat ventral tegmental area neurons: GABA phenotype and synapses onto dopamine and GABA cells. Synapse 63:895-906. CrossRef Medline

Omelchenko N, Bell R, Sesack SR (2009) Lateral habenula projections to dopamine and GABA neurons in the rat ventral tegmental area. Eur J Neurosci 30:1239-1250. CrossRef Medline

Paladini CA, Tepper JM (1999) GABA(A) and GABA(B) antagonists differentially affect the firing pattern of substantia nigra dopaminergic neurons in vivo. Synapse 32:165-176. CrossRef Medline

Parent M, Lévesque M, Parent A (2001) Two types of projection neurons in the internal pallidum of primates: single-axon tracing and three dimensional reconstruction. J Comp Neurol 439:162-175. CrossRef Medline

Perrotti LI, Bolaños CA, Choi KH, Russo SJ, Edwards S, Ulery PG, Wallace DL, Self DW, Nestler EJ, Barrot M (2005) DeltaFosB accumulates in a GABAergic cell population in the posterior tail of the ventral tegmental area after psychostimulant treatment. Eur J Neurosci 21:2817-2824. CrossRef Medline

Quinn HR, Matsumoto I, Callaghan PD, Long LE, Arnold JC, Gunasekaran N, Thompson MR, Dawson B, Mallet PE, Kashem MA, MatsudaMatsumoto H, Iwazaki T, McGregor IS (2008) Adolescent rats find repeated Delta(9)-THC less aversive than adult rats but display greater residual cognitive deficits and changes in hippocampal protein expression following exposure. Neuropsychopharmacology 33:1113-1126. CrossRef Medline

Rezvani AH, Sexton H, Levin ED (2010) Persistent high alcohol consumption in alcohol-preferring $(\mathrm{P})$ rats results from a lack of normal aversion to alcohol. Alcohol Alcohol 45:219-222. CrossRef Medline

Rigotti NA, Gonzales D, Dale LC, Lawrence D, Chang Y (2009) A randomized controlled trial of adding the nicotine patch to rimonabant for smoking cessation: efficacy, safety and weight gain. Addiction 104:266-276. CrossRef Medline

Riley AL (2011) The paradox of drug taking: the role of the aversive effects of drugs. Physiol Behav 103:69-78. CrossRef Medline

Rodd ZA, Melendez RI, Bell RL, Kuc KA, Zhang Y, Murphy JM, McBride WJ (2004) Intracranial self-administration of ethanol within the ventral tegmental area of male Wistar rats: evidence for involvement of dopamine neurons. J Neurosci 24:1050-1057. CrossRef Medline

Rodd ZA, Oster SM, Ding ZM, Toalston JE, Deehan G, Bell RL, Li TK, McBride WJ (2008) The reinforcing properties of salsolinol in the ventral tegmental area: evidence for regional heterogeneity and the involve- ment of serotonin and dopamine. Alcohol Clin Exp Res 32:230-239. CrossRef Medline

Rotllant D, Márquez C, Nadal R, Armario A (2010) The brain pattern of c-fos induction by two doses of amphetamine suggests different brain processing pathways and minor contribution of behavioural traits. Neuroscience 168:691-705. CrossRef Medline

Scammell TE, Estabrooke IV, McCarthy MT, Chemelli RM, Yanagisawa M, Miller MS, Saper CB (2000) Hypothalamic arousal regions are activated during modafinil-induced wakefulness. J Neurosci 20:8620-8628. Medline

Schultz W (1998) Predictive reward signal of dopamine neurons. J Neurophysiol 80:1-27. Medline

Shabat-Simon M, Levy D, Amir A, Rehavi M, Zangen A (2008) Dissociation between rewarding and psychomotor effects of opiates: differential roles for glutamate receptors within anterior and posterior portions of the ventral tegmental area. J Neurosci 28:8406-8416. CrossRef Medline

Shurman J, Koob GF, Gutstein HB (2010) Opioids, pain, the brain, and hyperkatifeia: a framework for the rational use of opioids for pain. Pain Med 11:1092-1098. CrossRef Medline

Smith Y, Bolam JP (1990) The output neurones and the dopaminergic neurones of the substantia nigra receive a GABA-containing input from the globus pallidus in the rat. J Comp Neurol 296:47-64. CrossRef Medline

Somogyi P, Bolam JP, Smith AD (1981) Monosynaptic cortical input and local axon collaterals of identified striatonigral neurons. A light and electron microscopic study using the Golgi-peroxidase transportdegeneration procedure. J Comp Neurol 195:567-584. CrossRef Medline

Spano MS, Fattore L, Cossu G, Deiana S, Fadda P, Fratta W (2004) CB1 receptor agonist and heroin, but not cocaine, reinstate cannabinoidseeking behaviour in the rat. Br J Pharmacol 143:343-350. CrossRef Medline

Stamatakis AM, Stuber GD (2012) Activation of lateral habenula inputs to the ventral midbrain promotes behavioral avoidance. Nat Neurosci 15: 1105-1107. CrossRef Medline

Tan KR, Yvon C, Turiault M, Mirzabekov JJ, Doehner J, Labouèbe G, Deisseroth K, Tye KM, Lüscher C (2012) GABA neurons of the VTA drive conditioned place aversion. Neuron 73:1173-1183. CrossRef Medline

Ungless MA, Whistler JL, Malenka RC, Bonci A (2001) Single cocaine exposure in vivo induces long-term potentiation in dopamine neurons. Nature 411:583-587. CrossRef Medline

Van Bockstaele EJ, Pickel VM (1995) GABA-containing neurons in the ventral tegmental area project to the nucleus accumbens in rat brain. Brain Res 682:215-221. CrossRef Medline

van Zessen R, Phillips JL, Budygin EA, Stuber GD (2012) Activation of VTA GABA neurons disrupts reward consumption. Neuron 73:1184-1194. CrossRef Medline

Yamaguchi T, Sheen W, Morales M (2007) Glutamatergic neurons are present in the rat ventral tegmental area. Eur J Neurosci 25:106-118. CrossRef Medline

Zahm DS, Becker ML, Freiman AJ, Strauch S, Degarmo B, Geisler S, Meredith GE, Marinelli M (2010) Fos after single and repeated selfadministration of cocaine and saline in the rat: emphasis on the Basal forebrain and recalibration of expression. Neuropsychopharmacology 35:445-463. CrossRef Medline

Zangen A, Ikemoto S, Zadina JE, Wise RA (2002) Rewarding and psychomotor stimulant effects of endomorphin-1: anteroposterior differences within the ventral tegmental area and lack of effect in nucleus accumbens. J Neurosci 22:7225-7233. Medline

Zangen A, Solinas M, Ikemoto S, Goldberg SR, Wise RA (2006) Two brain sites for cannabinoid reward. J Neurosci 26:4901-4907. CrossRef Medline 